\title{
Costs for the Development of a Virtual University
}

\author{
Murray Turoff \\ Distinguished Professor of Computer and Information Science \\ New Jersey Institute of Technology \\ email: turoff@eies.njit.edu \\ homepage url: http://eies.njit.edu/ turoff/ \\ (C) Copyright 1996 by Murray Turoff
}

\begin{abstract}
This paper is an update of one that the author published in 1982. It deals with the costs and effort required to set up a first class academic program for 2000 students that is made up of students and faculty scattered around the world. The establishment of such a University would cost less than the addition of a single classroom building on a physical college campus (approximately $\$ 15$ million US).
\end{abstract}

\section{KEYWORDS}

virtual university

cost analysis

policy issues

\section{INTRODUCTION}

The purpose of this paper is to describe the resources needed to implement a totally Virtual University. The students and faculty of this university could be located, on an individual basis, anywhere in the World. The costs estimates used are approximate but are still startling even if the error is as much as $20 \%$ in the wrong direction.

The financial assumptions are based on the principle of not limiting costs where it might degrade the quality of the education delivered. Furthermore there are a number of educational assumptions based upon earlier work with respect to the Virtual Classroom and Learning Networks ([1]; [2]; [3]; [4]; [5]). Some of the more critical assumptions are:

- The pedagogy will be based upon collaborative learning approaches where students do a significant part of course assignments as learning groups or learning teams.

- The University is able to utilize a group oriented communication system ([6]; [2]) that is able to support the special software structures and tools required to:

$\checkmark$ Augment and facilitate the learning process as has been done with the Virtual Classroom ${ }^{\circledR}$ system at NJIT ([1]).

$\checkmark$ Provide for individual, group, course, and university wide computer based "memories" in the context of a Computer Mediated Communications system ([6]).

$\diamond \quad$ Use collaborative oriented Hypertext creation capabilities ([8]).

$\diamond$ Use specialized computer based collaborative structures such as games, debates, GDSS and Delphi to augment the learning process ([9]; [10]).

$\diamond \quad$ Provide for information overload reduction through such facilities as computer based gradebooks, automatic notifications of events of concern, tracking of individual and class activities and status, automatic routing, categorization and organization of assignments ([1]). 
- The faculty are specifically hired because of their ability to adapt to the use of the underlying technology and to the facilitation, guidance, and leadership roles consistent with asynchronous based group learning.

- The faculty will utilize the technology to carry out all administrative and academic tasks including the group processes associated with the development and approval of curriculum for the various degrees to be offered.

- Internet or its future equivalent will be the communication network in which this particular university learning network will exist.

Given the above basic assumptions, and caveats that one can in fact hire outstanding people with respect to the approach to be taken, and that an integrated group oriented software system dedicated to the learning mission is available, we can proceed with the determination of the actual costs.

\section{COMPUTER EQUIPMENT COSTS}

What we need is a fairly powerful network server to provide the database and conferencing capabilities for the students and faculty. Initially we will be servicing about 2500 users. In the long run graduates will have a permanent account so that over ten years we will build up to about 8000 users. We expect to be offering regular updating courses to all our alumni.

Even with allowances for some video equipment to reproduce videotapes and to create CD ROMS of course material produced by the faculty, the initial hardware investment would not be more than about $\$ 100,000$. We amortize this over five years and allow a $10 \%$ interest rate. We also assume we are going to invest $\$ 20,000$ a year in new equipment. This results in an assumed yearly rate of $\$ 50,000$ for equipment.

Providing students with an updated CD-ROM every year and some number of video tapes will require no more than $\$ 50,000$ for supplies associated with the computer operation.

Finally, we will allow a software cost of $\$ 50,000$ a year as well. This then means a total of $\$ 150,000$ a year for costs associated with the computer system.

\section{PHYSICAL CAMPUS COSTS}

We do need a place to house the administrative and technical people. A large town house in some reasonable area for real estate would be sufficient. Let us assume we pay about $\$ 500,000$ for this facility. We will amortize this over 10 years at the same 10\% rate. This results in $\$ 100,000$ a year for the building. We should pick a good weather area where we don't have to worry about excessive upkeep costs. In any case we will allow $\$ 50,000$ a year for maintenance and upkeep. We thus total $\$ 150,000$ a year for the costs of the physical campus.

\section{NON FACULTY PERSONNEL}

We will need a good business manager to head the administrative side of the operation but there will be no academic administrators. All academic decisions on courses and such will be made by the faculty on an individual, discipline, and full faculty basis. However, there will be an ability on the part of the business manager to remove faculty for poor teaching performance based upon a 
regular evaluation by a full time social scientist who will conduct a regular analysis of feedback from the students.

We will employ four full time administrative staff to handle such things as record keeping, reports, distribution of student material, etc.

Furthermore we will employ four full time technical people, not only to keep up the system, but to be on call for the students to aid in any technical problems they will have.

The above is a non faculty staff of ten individuals, all of whom will be paid the same salary of $\$ 100,000$ (US) a year. We wish to avoid any occurrence of Peter's principle. There is no need in this organization to move up in the hierarchy and we expect all the staff to back one another up when needed in some of the crunch efforts that can occur at the beginning and end of the semesters.

We assume about $\$ 50,000$ of indirect costs and benefits for each of these employees and the result would thus be $\$ 1,500,000$ a year for these ten employees.

\section{SUMMARY OF ALL NON FACULTY COSTS}

The result for all non-faculty costs are as follows:

\section{A. Non Faculty Costs}

\begin{tabular}{|l|r|}
\hline \multicolumn{1}{|c|}{ Type of Cost } & \multicolumn{1}{|c|}{ Yearly Total } \\
\hline Non Faculty Personnel & $\$ 1,500,000$ \\
\hline Physical Campus Costs & $\$ 150,000$ \\
\hline Computer Equipment \& Software & $\$ 150,000$ \\
\hline Total & $\$ 1,800,000$ \\
\hline Costs per student per year based upon 2,000 students & $\$ 900$ \\
\hline
\end{tabular}

Basically all the costs not associated with faculty salary are under $\$ 1000$ a year per student. One should compare this with the costs of upkeep for a physical campus to understand what a tremendous savings this is. One would expect the physical plant in a traditional University or College to be as much as half the total cost.

In 1982 when we first did this analysis the resulting cost per student was about $\$ 5,000$. This was because of much larger costs for the computer equipment and the costs of the network to tie the students together in the United States. In the current analysis we can assume that the students, as well as the faculty and other employees, will bear the costs of tying into the Internet (\$15-20 dollars per month for unlimited use in the US). We are also going to assume that the students will make their own investments in the required multimedia computers and software. Having network access and required hardware and software is part of being an intelligent citizen in today's society, or at least it should be!

The costs to the individual of computer equipment and the network connection are far less than the costs of upkeep for a car or for most other means of transportation over any significant distance. Another relative comparison one can make is to the cost of travel to a college and/or the cost of room and board for being able to live on campus. All of these would make the investment in a personal computer and useful software a relatively attractive cost alternative. 
For individuals interested in distance education, it is becoming an assumption that they are going to make the investment in computer systems to be able to take remote courses. While Internet costs in some countries may still be restrictive, the costs in the US are more indicative of what true costs should be.

\section{FACULTY COSTS}

Our faculty are also going to get $\$ 150,000$ (US) a year in salary and benefits. However, they have their choice as to taking it all in salary as a services contract or in utilizing certain benefit packages for retirement, medical, etc. However, since our faculty may live anywhere in the world they may prefer to arrange their own benefits as self-employed individuals to be consistent with whatever situation exists in the places they are living.

We also expect the faculty to supply their own equipment and software out of this rather liberal salary/contract amount. Given today's technology instructors could set up their own ability to handle multimedia (scanning, voice integration) and even to produce their own home grown video based lectures to distribute to students. The total cost of all the equipment today would be under $\$ 20,000$ for what would be a very acceptable production facility.

We will probably offer three-year contracts when a person is initially hired and go to a five-year contract after that with a right of renewal dependent upon the evaluation ratings the instructor receives in the prior five years. We will also allow for faculty who want to teach on a halftime load but on a regular contract, subject to the same conditions. If the institution is research oriented the arguments to have tenure are still valid and important. However, tenure should not force the termination of faculty who are only teaching oriented.

We are generally talking about a teaching oriented program. Certainly an institution offering a graduate program should have a reasonable amount of research associated with the graduate areas. However, for cost purposes the distinction between a teaching and a research oriented institution is really the number of courses an instructor must teach for the specified salary. We can assume a teaching institution would require the instructor to teach four courses a semester for two semesters a year while a research institution would require only two courses a semester for two semesters a year. In addition we would offer three semesters a year (summer being a third semester) and allow faculty to vary which of the three semesters they want as vacation.

In determining the actual faculty for two thousand students there are a number of different dimensions to consider:

- How many courses is a professor required to teach in a given semester? We are using four courses and two courses a semester as representative of a teaching and a research institution respectively.

- How many different majors or degrees are supported? This determines how many different courses are offered in the total curriculum. For simplicity we will assume that about 20 courses are common and 20 are unique to a given major. For averaging purposes we will just utilize 20 unique courses as the number needed to create a major or discipline oriented degree.

- The other related factors are the number of students per class, the student to faculty ratio, the total number of faculty and the total number of unique courses offered. 
The following table summarizes the alternatives one might choose for an institution of 2000 students by varying many of the above factors within reasonable ranges. Given the salary of a faculty member as $\$ 150,000$ this allows us to determine the tuition per year that each of the students must pay or the cost for a single course, assuming a load of 10 courses a year (two semesters) per full time student.

A. Basic Assumptions

\begin{tabular}{|c|l|r|r|r|r|}
\hline $\begin{array}{l}\text { Alternative } \\
\text { Exemplars }\end{array}$ & $\begin{array}{l}\text { Number of } \\
\text { Unique } \\
\text { Courses }\end{array}$ & $\begin{array}{l}\text { Number of } \\
\text { Majors or } \\
\text { Degrees }\end{array}$ & $\begin{array}{l}\text { Number of Instructors } \\
\text { and student to faculty } \\
\text { ratio }\end{array}$ & $\begin{array}{l}\text { Classes taught } \\
\text { per Semester } \\
\text { per Instructor }\end{array}$ & $\begin{array}{l}\text { Students } \\
\text { per Class }\end{array}$ \\
\hline $1 . \mathrm{a}$ & 200 & 10 & $5040: 1$ & 4 & 50 \\
\hline $1 . \mathrm{b}$ & 200 & 10 & $10020: 1$ & 2 & 50 \\
\hline $2 . \mathrm{a}$ & 400 & 20 & $10020: 1$ & 2 & 25 \\
\hline $2 . \mathrm{b}$ & 400 & 20 & $20010: 1$ & 4 & 25 \\
\hline $3 . \mathrm{a}$ & 600 & 30 & $15016: 1$ & 2 & 17 \\
\hline $3 . \mathrm{b}$ & 600 & 30 & $3008: 1$ & 4 & 13 \\
\hline $4 . \mathrm{a}$ & 800 & 40 & $20010: 1$ & 2 & 13 \\
\hline $4 . \mathrm{b}$ & 800 & 40 & $4005: 1$ & & \\
\hline
\end{tabular}

\section{B. Resulting Costs}

\begin{tabular}{|c|c|c|c|c|c|}
\hline $\begin{array}{l}\text { Alternative } \\
\text { Exemplars }\end{array}$ & $\begin{array}{l}\text { Total } \\
\text { Salar } \\
\text { \$) }\end{array}$ & $\begin{array}{l}\text { Faculty } \\
\text { (million }\end{array}$ & $\begin{array}{ll}\text { Tuition } & \text { pe } \\
\text { year } & \text { pe } \\
\text { student } & \end{array}$ & $\begin{array}{l}\text { Tuition pe } \\
\text { Course }\end{array}$ & Remark \\
\hline 1.a & & 7.5 & 3,75 & 37 & Community College \\
\hline 1.b & & 15.0 & 7,500 & 75 & like range \\
\hline $2 . \mathrm{a}$ & & 15.0 & 7,500 & 75 & Desirable teaching College \\
\hline 2.b & & 30.0 & 15,000 & 1,50 & Desirable research University \\
\hline 3.a & & 22.5 & 11,25 & 1,12 & Graduate School \\
\hline 3.b & & 45.0 & 22,500 & 2,25 & like Range \\
\hline $4 . \mathrm{a}$ & & 30.0 & 15,000 & 1,50 & Prestigious Teaching College \\
\hline $4 . \mathrm{b}$ & & 60.0 & 30,000 & 3,00 & Prestigious Research University \\
\hline
\end{tabular}

To the above tuition figures we add about $\$ 1000$ per year for all other expenses. As a result we see that the principal cost ( $80 \%$ or more) is faculty salaries. We have chosen those faculty salaries to be able to obtain the very best faculty. Usually the assumption about a distance learning program is that it will always be inferior to a face-to-face program on a college campus. We strongly believe the quality of the program is determined by the quality of the instructors and the tradition or culture of their institution that in turn influences their teaching methods. With the assumptions above, this Virtual University can be as good as any University anywhere in the world that it wishes to compete with.

Today state funded colleges and Universities in the US are charging about $\$ 5,000$ tuition per year but this represents only about $1 / 3$ the actual costs, with the rest being funded through taxes. The above table illustrates that a range of $\$ 5,000$ to $\$ 15,000$ competes with any state institution on a total cost basis. Governments would get a lot more for their money by investing in a first class distance program rather than in more second class physical campuses. 
Private colleges and universities are today in the $\$ 10,000$ to $\$ 30,000$ (US) range and that is exactly where the options above fall. In fact, for the learning approaches recommended, a class size of 25 in an undergraduate degree is far more desirable than trying to go to the much smaller class size typified by the higher tuition options. Working teams of students should be in the three to seven range and one would like to have at least three to five teams in a class. In addition a class of twenty-five is more likely to generate a reasonably active discussion than classes of 10-15 students. As students progress to upper division and to graduate courses, the critical mass for good discussion goes down as each student becomes more of an expert in the subject matter and usually has more inherent incentive to participate.

The other key driving parameter besides class size is the number of unique courses which for case 2 was about 20 different majors (400 unique course) or degrees. For 2000 students this is about 100 majors for each degree, on the average. However, the number of majors in a given area will have extreme variation. The critical factor is having enough students in a given degree (even with multiple majors) so the students as a group can form a community and undertake various activities as a collaborative group.

While it is usually assumed in face-to-face classes that smaller class sizes are desirable, that is not the sole determining factor in the asynchronous electronic based discussion environment. The effort to teach in this medium is linearly proportional to the number of students in a class once you obtain critical mass. The technology is not a mechanism to generate large class sizes or to increase the efficiency of the educational process. It is really a technology to increase the effectiveness. This is not a message that college administrators as yet understand.

Given your own assumptions about what is the desirable makeup in a teaching college or a research university one can fill in the numbers they prefer. If one wants to settle for an "average" faculty where the average salary is not $\$ 150,000$, this Virtual University is going to be a lot cheaper. Essentially we have decided to shift the use of funds from the physical plant to the faculty and for that reason the numbers above come out to be very much like current institutions with respect to total tuition. We have done this to remove any doubt that for the same investment we could start a pure distance institution that is made up of far higher quality faculty on the average than most existing institutions.

Somewhere between $\$ 15$ and $\$ 30$ million would allow the formation of the University and one year of operation. If each new student (500 a year) where given an initial year of free tuition one could easily build up to the self sustaining figure of 2000 in four years and the initial funding would allow this to be the start up approach. One is talking about a total cost in the same range as a new building on an existing campus. Surely there is someone who would prefer to have their name on a College or University rather than a building!

\section{MANAGEMENT PRAGMATICS}

One could argue that excellent educators and others, who are retired, would work for considerably less. The average adjunct teacher at most Colleges is paid a fifth of what regular faculty are paid to teach the same course. Someone who is retired or seeking part time work will be willing to work for much less than regular salary. This is the common thinking of most current administrators and they seek to increase the amount of adjunct teaching as a way of reducing costs. Of course, there is good reason why accrediting agencies are concerned with the amount of adjunct teaching in any 
accredited program. There is also something philosophically wrong with the thinking of any academic institution when they claim they are going to offer the same quality education over the long term by hiring educators at one fifth the cost. The obvious possible conclusions are:

- they are paying regular faculty too much;

- regular faculty are not delivering more quality than adjuncts;

- adjunct-led education has less quality then the regular faculty;

- we are overproducing Ph.D.'s in some fields.

The budget cutting being fostered upon higher education may very well make Doonsbury's cartoons about the auctioning of individual courses to unemployed, untenured faculty a realistic forecast.

If we wish to best employ the concepts of a free enterprise system we should be paying for the quality we expect to deliver. As the universities and colleges enter a marketplace economy, the current conditions that make adjuncts cheaper will prove to be a transient situation. Many administrators in the past felt that distance programs would be cheap and profitable because they could be manned by adjuncts and separate from the regular on campus courses. It was not too long ago that university administrators would justify paying a woman less because they were the second salaried person in the family. Those who think that retired people should be paid less because they are retired are using the same view of the world. The ultimate solution would be for the accreditation agencies to wake up to reality and accredit the individual instructors.

In a network organization we are really eliminating the traditional hierarchy and people are hired into positions where there is no mobility. As a result we can eliminate the effect of Peter's Principle and if the manager responsible for hiring is the exceptional type, we should be able to avoid many of the classic problems that Dilbert has so beautifully expressed. There is no substitute for hiring top talent and we have to assume top talent for every position in the organization. This is why we want to have salaries that will attract top talent to apply. We expect the faculty in this institution to be able to master and utilize the emerging multimedia technology and to adopt whole heartily a collaborative approach to learning. Those expecting teaching "as usual" need not apply.

We do think that tenure is extremely important if a University is dedicated to a tradition of scholarship and that at least a core group in a given discipline area should have tenure. Faculty governance over the subject matter and program in a given field is key to outstanding educational programs. However, it is doubtful that all the faculty would be interested in being tenured and it should be expected that the idea of part time and full time adjunct professors would be utilized on a one to five year contractual basics. However, they will not be paid less than tenured faculty. There will be no automatic out if tenure is not obtained.

There does need to be intelligent assessment of the course delivery effectiveness. Part of this should be professional assessment and interpretation of the feedback from the students. When one can review the whole transcript of a single course's class discussion and associated assignments, it is quite easy to make a very direct assessment of both the nature of the delivered material and the response of the students to it. It may thus be easier to evaluate course delivery in the virtual realm than in the physical one. Also one would expect the degree programs to be accredited in the normal manner.

The lifetime networks that universities aid in establishing for their students can be fostered through the electronic environment just as easily as through the physical campus. The technology of 
networking allows social-emotional exchanges ([2]) as well as professional ones and the fostering of collaborative-oriented education will probably create a more widespread equality of human networking. We note that a number of universities are now offering their alumni email addresses through the university (e.g., Princeton) and beginning to offer other network services to alumni as well as students.

For brick and mortar colleges one can expect the instructional budget to be only about $50 \%$ of the total budget and the faculty salary to be about $25 \%$ of the total budget. Clearly we are talking about an institution where faculty salary is to be $80-90 \%$ of a teaching institution and might drop to less for a research institution requiring physical laboratory facilities. This institution does not have to provide a lot of things that a physical campus provides and it is there to serve mature students who are concerned with learning. We expect students to obtain counseling and advice from faculty, and faculty to be willing to form closer relationships with individual students.

Perhaps the one lack in this institution is an outstanding library. However, many college libraries today are being shortchanged budgetwise (e.g., they are often the first line item to be cut) so that they do not provide collections that are any better than what might be expected to become available in the future on CD-ROM and over the net. There are many economical services for the reprint of professional material needed for particular courses and this will adequately serve bachelor and master courses. One could create a set of CD-ROM filled with all the material needed for a particular degree and pay appropriate royalties for limited distribution of the material.

Other services universities recently provide, such as placement might be improved if they are unbundled. Professional services in this area are usually better than those at colleges and universities.

Once upon a time it was possible to be the writer, printer, publisher, and distributor of information as a single individual (e. g., Ben Franklin). For faculty who master the emerging technology it is now possible for them or others to become both authors and distributors with no middlemen ([12]). What inventory systems did to the wholesale industry, the web will do to the publishing industry. Faculty member can become their own publishers of course material ([14]; [13]). The amount of course material already on the Web is already large and growing and in some cases access codes are now being required to be able to utilize it. Automatic charging facilities directly for the author's use will soon follow.

This paper raises a lot of issues that cannot be answered within the initial objective of examining the underlying possible cost comparison between a true Virtual University and a brick and mortar version. However, these issues are worthy of further discussion and consideration for the future of ALN delivery modes:

- What is the nature of quality with respect to faculty and to courses?

- How does one insure quality and how does one measure it?

- How does one effectively utilize student input to evaluate courses, faculty and programs?

- How does one insure quality management decisions on hiring and retention of faculty?

- How does one tell a faculty member is going to be good at teaching with the associated technology?

- How does one insure the social and emotional benefits of a higher educational institution in the virtual environment? 
- How does the student know what he/she is getting?

Most of these questions apply equally well to brick and mortar institutions which we know are all over the map with respect to quality and with respect to costs. We cannot help but note that the intelligent prospective student can find out more today about what they will be learning at a given institution by going to the Web rather than getting the standard mail-out materials and the usual college catalog.

\section{SUMMARY OBSERVATIONS}

Like all innovations, the reality may not always live up to the dream. Some instructors will take the course they have been teaching in a face to face mode and translate it just as it is to this technology. In fact, they will assign a graduate student TA to lead the on-line discussion and treat it as solely a question-answer dialogue or a problem discussion section normally led by a Teaching Assistant. Under these circumstances there will be little chance of improving the quality of the educational process. It will be the usual approach to computerization of merely automating what already occurs in the physical environment, instead of a careful consideration of what are the new opportunities for improved change in the learning process.

Instead of improving the direct relationship between instructor and students, the technology can be used to accomplish the complete opposite, and more thoroughly isolate the content experts from the learners. Given the current administrative and budget trends in US Colleges and Universities this could very well become the mode of utilization for the technology. The idea that everyone must have a college education and therefore that it has to be a lot cheaper might be part of the disease that is plaguing colleges and universities. Increasingly colleges are being forced to make up the shortcomings of public K-12 educational systems. It might be that creating a free nationwide virtual high school might be one of the greatest boosts possible for improving college and university education. It would be far cheaper than all the remedial efforts now common at most colleges and universities.

There is no real effectiveness benefit in this technology unless it incorporates changes to the learning approach itself. The fundamental change that has paid off in our studies of the impact is that of the use of collaborative learning and the development of students into a learning community. The full impact of this has yet to be seen because today most changes have occurred at the level of a single course. The potential development of learning teams and projects that persist across courses has yet to be explored in any effective manner. Consider for example the typical business game to simulate a company and its performance during a single course. What would happen if this company existed through a series of courses and as the students move to more advanced courses they could become high level managers and/or project teams in the "company." The same might be done for a large scale engineering project in teaching students for various low to high level design efforts in the project. The same concept can also be applied in such areas as sociology, political science, and architecture.

As we see more complete degree programs develop in this area there will be more opportunity to explore rather dramatic departures from the current approach to curriculum. In fact, these types of distance programs will be attracting more of the more valuable professionals and managers in organizations who are too over committed today to take advantage of face-to-face programs and who are too negative on the quality (as valuable learning experiences) of current distance programs 
to consider them as a serious option. Trying to test these new approaches on the current generation of distance students is highly misleading because almost anything is considered by them an improvement to the old approach of isolated distance students in a one on one approach with an instructor.

There are many possible concepts that have not been tested yet that are now possible in the virtual environment. What about learning teams that stay together across a set of courses in a given program? What about such teams moving at their own pace through the material? What about exercises and projects that stretch out through a series of courses that deal with the situation at different levels? Might some of these approaches be a significant improvement on current educational practices?

For those of us who are still located in a traditional higher educational environment the real dramatic change is to have the use of Group Oriented Communication Systems to support regular courses and to integrate the distance students as full participants in the regular face-to-face class. For those of us who have done this we believe the result has been a considerable improvement in the quality of face-to-face classes as well as the benefits for the distance student. Furthermore one has the distinct impression that many of the distance students we are seeing in such programs are those who would not tolerate the second class education that one often associates with the concept of a distance program.

Our greatest danger is from administrators both in colleges and in state and local governments who think computerization will bring about cheaper higher education courses. It can only happen for those things that are learned by drill and practice but not for the things most of us consider at the core of what we are teaching the nature of problem solving and the associated thinking process in given application domains.

\section{ACKNOWLEDGMENT}

I would like to thank the reviewers for the ALN Journal for their comments. This caused me to add the section on Management Pragmatics which, hopefully, will cause some additional discussion about this paper.

\section{REFERENCES}

1. Hiltz, S. R. , The Virtual Classroom: Learning Without Limits Via Computer Networks, Norwood, NJ: Ablex Publishing Corporation, Human-Computer Interaction Series, 1994.

2. Hiltz, S. R. and Turoff, M., The Network Nation: Human Communication via Computer, Addison Wesley Advanced Book Program, 1978. Revised edition published by MIT Press, 1993.

3. Harasim, Linda, Hiltz, Starr Roxanne, Teles, Lucio, \& Turoff, Murray, Learning Networks: A field guide, MIT Press, 1995.

4. Turoff, Murray and Hiltz, S. R., Remote Learning: Technologies and Opportunities. Proceedings, World Conference on Continuing Engineering Education, 1986.

5. Turoff, Murray, On the Design of an Electronic University, in Proceeding of the conference on Telecommunications and Higher Education, published by NJIT, April, 1982.

6. Turoff, Murray, Computer Mediated Communication Requirements for Group Support, Journal of Organizational Computing, Volume 1, Number 1, 1990.

7. Turoff, Murray, The EIES Educational Experience, in Proceedings of the Conference on Telecommunications and Higher Education published by NJIT, April, 1982. 
8. Turoff, Murray, Rao, Usha, \& Hiltz, S. R., Collaborative Hypertext in Computer Mediated Communications, Proceeding of the Hawaii International Conference on Systems Science, Volume 4, January, IEEE Computer Society, 357-366, 1991.

9. Hsu, Enrico Y. P., Hiltz, S. R., and Turoff, Murray, Computer-Mediated Conferencing System as Applied to a Business Curriculum: A Research Update. In V. S. Jacob and H. Pirkul, eds., The Impact of Information Technology on Business Schools: Research, Teaching and Administration, Proceedings of the 20th Annual North American Conference of the International Business School Computer Users Group, pp. 214- 227. Awarded "Best Paper- Teaching", 1992.

10. Turoff, Murray, S. R. Hiltz, A. N. F. Bahgat, and Ajaz Rana, Distributed Group Support Systems, MIS Quarterly; December 1993, 399-417, 1993.

11. Hiltz, S. R. and Turoff, Murray, Structuring Computer-Mediated Communication to Avoid Information Overload, reprint of previously published paper, in D. Marca and G. Bock, eds., Groupware: Software for Computer-Supported Cooperative Work, Washington D. C., IEEE Computer Society Press, 1992, pp. 384-393, 1992.

12. Turoff, Murray, A Marketplace Approach to the Information Highway, Boardwatch Magazine, April, 1995. Updated version in NJIT Magazine, Fall, 1996.

13. Turoff, Murray, \& Starr Roxanne Hiltz, Software Design and the Future of the Virtual Classroom, Journal of Information Technology for Teacher Education, Volume 4, Number 2, 1995, 197-215.

14. Turoff, Murray, Information \& Value: The Internal Information Marketplace, Journal of Technological Forecasting and Social Change, Volume 27, Number 4, July, 357-373, 1985. 